\title{
PERENCANAAN STRATEGIS TEKNOLOGI INFORMASI: Studi Kasus Pada Perguruan Tinggi Lepisi Tangerang
}

\author{
Ahmad Yani ${ }^{1}$,M.Sukrisno Mardiyanto ${ }^{2}$ \\ Universitas Bina Sarana Informatika ${ }^{1}$, \\ STMIK Nusa Mandiri Jakarta ${ }^{2}$ \\ ahmad.amy@bsi.ac.id'1, smirzap@gmail.com²
}

\begin{abstract}
The use of information technology for any modern organization is a must, because it will greatly assist management in managing and achieving organizational goals. To implement information technology in organizations it is necessary to plan the right strategy. Information Technology strategic planning is a process of identifying a portfolio of computer-based information system applications that will support organizations in implementing business plans and realizing their business goals. Information Technology strategy planning studies the influence of Information Technology on business performance and contributions to organizations in choosing strategic steps. In the Information Technology strategic planning process with the research object of LEPISI College, the author uses the framework according to Jhon Ward and Peppard. The results of this study are in the form of a proposed Information System strategy planning framework that can be used in LEPISI colleges.
\end{abstract}

Keyword: Information Technology Strategic plan

\begin{abstract}
ABSTRAK
Pemanfaatan teknologi informasi bagi organisasi apapun yang modern adalah suatu keharusan, karena akan sangat membantu manajemen dalam mengelola dan mencapai tujuan organisasi. Untuk mengimplementasikan teknologi informasi dalam organisasi diperlukan perencanaan strategi yang tepat. Perencanaan strategis Teknologi Informasi merupakan suatu proses identifikasi portofolio aplikasi sistem informasi berbasis komputer yang akan mendukung organisasi dalam pelaksanaan rencana bisnis dan merealisasikan tujuan bisnisnya. Perencanaan strategi Teknologi Informasi mempelajari pengaruh Teknologi Informasi terhadap kinerja bisnis dan kontribusi bagi organisasi dalam memilih langkah-langkah strategis. Dalam proses perencanaan strategis Teknologi Informasi dengan obyek riset Perguruan Tinggi LEPISI ini, penulis menggunakan framework menurut Jhon Ward dan Peppard Hasil dari penelitian ini adalah berupa usulan kerangka kerja perencanaan strategi Sistem Informasi yang dapat digunakan pada perguruan tinggi LEPISI.
\end{abstract}

Kata kunci: Perencanaan Strategis Teknologi Informasi 


\section{PENDAHULUAN}

Kemudahan pelayanan serta kualitas layanan yang diberikan perguruan tinggi akan diapresiasi oleh masyarakat yang akan melanjutkan pendidikan hingga pendidikan tinggi. Sehingga akan banyak masyarakat yang mempercayakan pendidikannya pada perguruan tinggi. Perguruan tinggi yang dapat memberikan pelayanan jasa pendidikan yang baik kepada mahasiswanya akan banyak diminati oleh masyarakat. Pemberian pelayanan yang baik yang diberikan kepada masyarakat umumnya dan kepada sivitas akademik perguruan tinggi akan sangat didukung oleh adanya Sistem Informasi yang dimiliki oleh perguruan tinggi. Sistem Informasi yang baik sangat dipengaruhi oleh pemanfaatan Teknologi Informasi. Dengan semakin berkembangnya jumlah perguruan tinggi swasta di Tangerang saat ini, maka menyebabkan perlunya perencanaan strategis Sistem Informasi Akademik dan Teknologi Informasi untuk tetap eksis dan memenangkan persaingan dalam dunia pendidikan tinggi. Pada era teknologi informasi ini, hampir semua organisasi memanfaatkan IT dalam kegiatan operasionalnya. Akan tetapi kemampuan perencanaan, pengelolaan dan implementasi SI/TI yang dikaitkan dengan strategi bisnis organisasi nampaknya masih kurang diterapkan. Adanya dukungan teknologi dan informasi yang baik pada suatu perusahaan akan meningkatkan efisiensi, efektifitas, serta produktifitas dalam menjalankan proses bisnis serta dapat mendukung pengimplementasian rencana strategis SI/TI-nya. Penelitian ini dilakukan untuk mengidentifikasi faktor-faktor yang mempengaruhi dalam perencanaan strategis Sistem Informasi Akademik yang akan diimplementasikan di Perguruan Tinggi LEPISI Tangerang. Berdasarkan perkembangan permasalahan yang ada di Perguruan Tinggi LEPISI Tangerang, maka diperlukan perencanaan strategis sistem informasi yang sesuai dengan organisasi untuk mendukung implementasi dalam bentuk yang lebih terpadu guna membenahi keadaan infrastruktur seperti pengembangan arsitektur jaringan, pengembangan laboratorium, peningkatan sarana dan prasarana, pengembangan sumberdaya manusia serta pengembangan aplikasi Sistem Informasi Akademik. Adapun pertanyaan penelitian tersebut adalah "Bagaimana bentuk rumusan tahapan penyusunan perencanaan strategis Sistem Informasi yang sesuai untuk Perguruan Tinggi LEPISI Tangerang dengan memperhatikan langkah-langkah dari perencanaan strategis suatu perguruan tinggi swasta?"

\section{PERANCANGAN PENELITIAN}

Perancangan rencana strategi SI/TI dalam penelitian ini, penulis mengacu pada metodologi Perencanaan Strategi Sistem Informasi yang dikemukakan oleh Jhon Ward dan Peppard[1]. Penggambaran secara garis besar mengenai metodologi yang akan digunakan dapat dilihat pada gambar berikut ini:

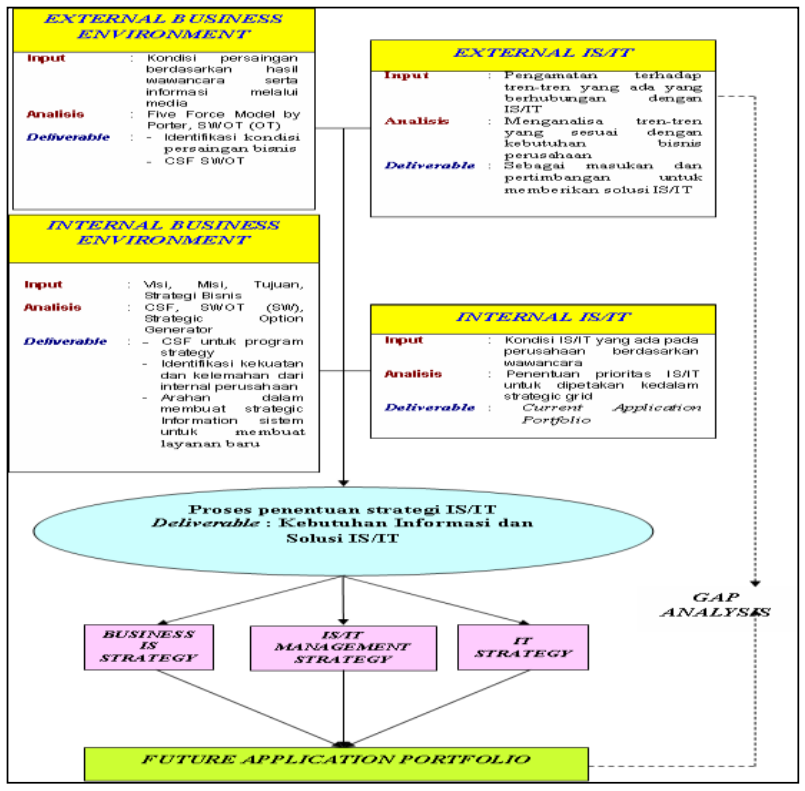

Sumber:(Ward dan Peppard,2002)

Gambar 1. Metodologi Penelitian

Versi Ward and Peppard

Berdasarkan Metode Pemetaan

102 | Jurnal PETIR 
Penelitian ini dilakukan dalam suatu organisasi yang sudah memiliki rencana bisnis yang berisi Misi, Visi, Tujuan dan Sasaran. Untuk mempertahankan bisnis yang sudah berjalan dan untuk mendapatkan kemampuan bersaing dengan pesaingnya, organisasi ingin membuat rencana strategi SI/TI. Rencana SI/TI bertujuan untuk mengevaluasi strategi bisnis saat ini agar selaras dengan strategi SI/TI serta mencari peluang bisnis baru dengan adanya dukungan SI/TI. Agar rencana strategi ini dapat dibuat dengan baik maka diperlukan suatu alur kerja perencanaan strategi SI/TI yang nantinya akan diusulkan sebagai kerangka kerja perencanaan strategi SI/TI yang nantinya akan diusulkan sebagai kerangka kerja perencanaan strategi SI/TI yang dapat diimplementasikan dalam suatu organisasi. Sebagai gambaran berikut ini kerangka kerja penelitian yang penulis gunakan.

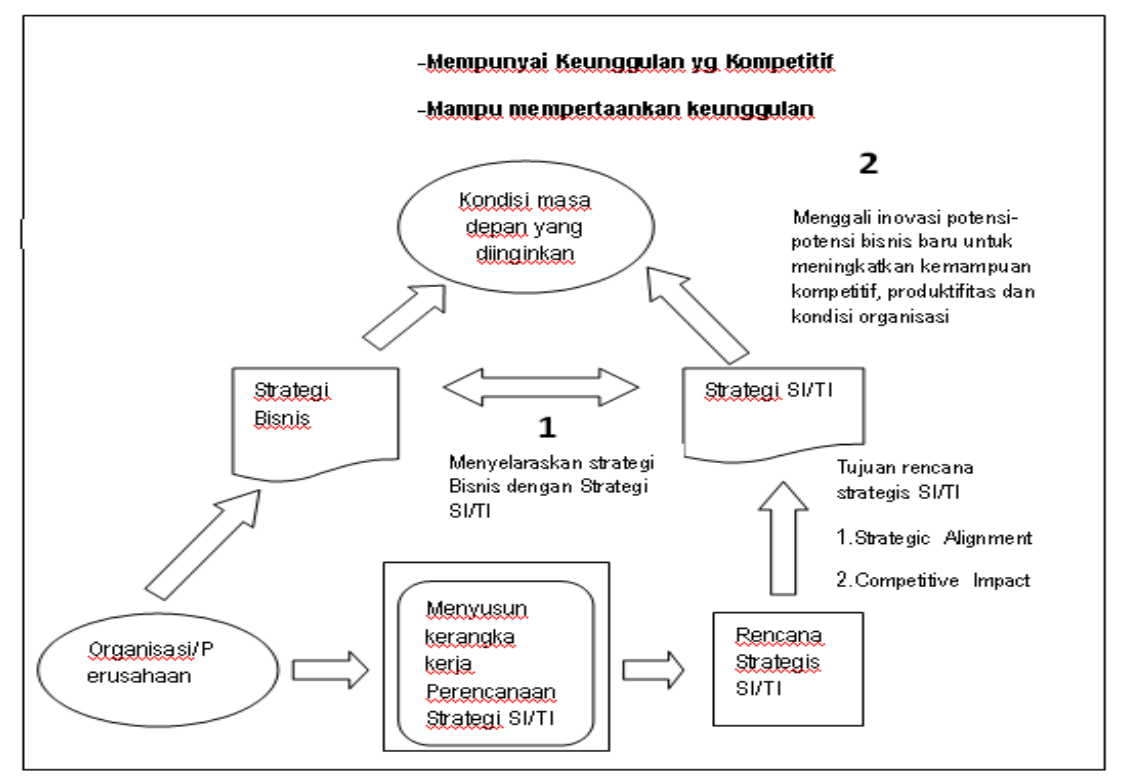

Gambar 2. Kerangka Kerja Penelitian

\section{Kerangka Kerja Perencanaan Strategi SI/TI}

Kerangka Kerja Perencanaan Strategi SI/TI merupakan acuan yang dapat memberikan gambaran kegiatan yang menyusun perencanaan strategi SI/TI. Kerangka kerja yang penulis maksud digambarkan sebagai berikut:

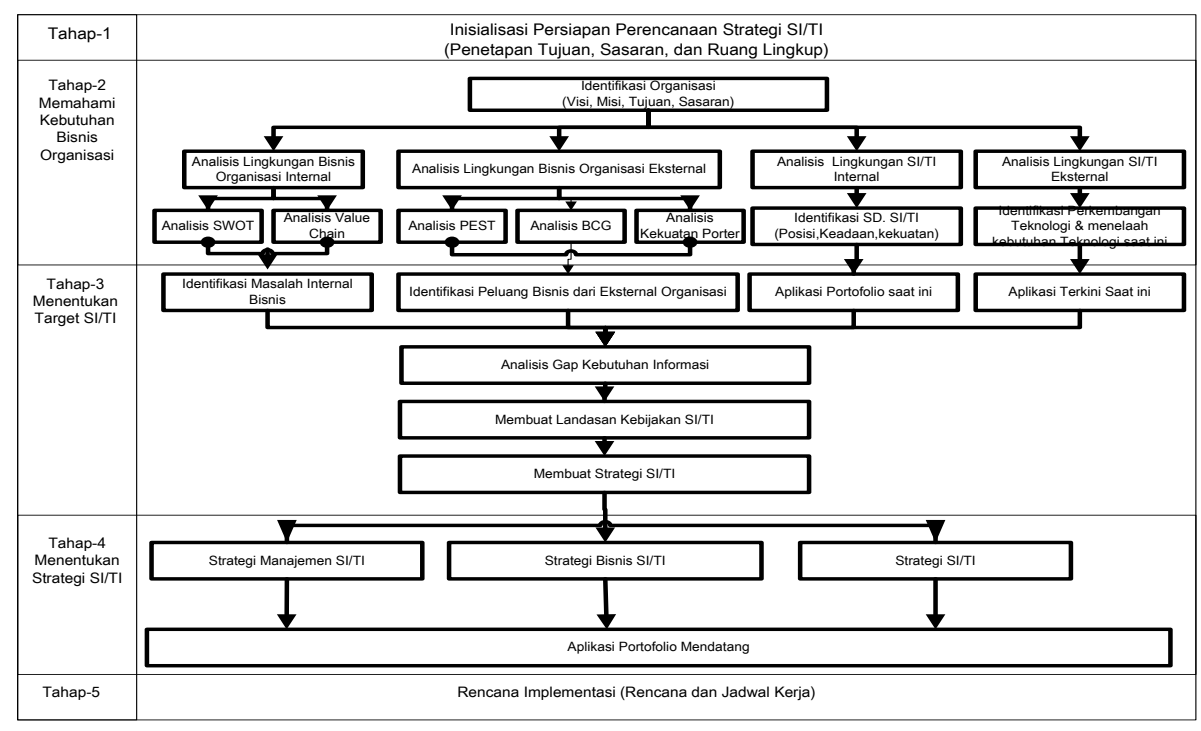

Gambar 3. Kerangka Kerja Perencanaan Strategi SI/TI. 
Untuk menunjang kelengkapan data penelitian yang dibutuhkan pada saat melakukan wawancara dengan narasumber, penulis membuat kisi-kisi instrumen penelitian yang bisa dilihat dalam tabel berikut:

Tabel 1. Kisi-kisi Instrumen Penelitian

\begin{tabular}{|c|c|}
\hline Dimensi & Indikator \\
\hline 1. Strategi Bisnis & $\begin{array}{l}\text { a. Memberikan pelayanan yang baik b. Melakukan kerja sama } \\
\begin{array}{ll}\text { c. Merspon perkembangan TI } & \text { d. Merespon perubahan bidang pendidikan }\end{array}\end{array}$ \\
\hline 2. Pemanfaatan SI/TI & $\begin{array}{l}\text { a. Memiliki SIA } \\
\text { b. Memanfaatkan TI secara optimal }\end{array}$ \\
\hline 3. Kebijakan di SI/TI & $\begin{array}{ll}\begin{array}{ll}\text { a. Memiliki divisi TI } & \text { b. Memiliki SOP } \\
\text { c. Asset hardware \& software } & \text { d. Memiliki web }\end{array}\end{array}$ \\
\hline $\begin{array}{l}\text { 4. Rencana strategis } \\
\text { SI/TI }\end{array}$ & $\begin{array}{l}\text { a. Memiliki renstra SI/TI } \\
\text { b. Harapan terhadap SI/TI untuk lembaga }\end{array}$ \\
\hline $\begin{array}{l}\text { 4. Dukungan lembaga } \\
\text { /manajemen }\end{array}$ & $\begin{array}{l}\text { a. Dukungan manajemen terhadap SI/TI } \\
\text { b. Harapan untuk lembaga }\end{array}$ \\
\hline
\end{tabular}

\section{HASIL DAN PEMBAHASAN}

Berdasarkan kerangka kerja perencanaan strategis SI/TI yang penulis usulkan sebelumnya, maka pada pembahasan ini dilakukan implementasi dari kerangka kerja tersebut guna membuat perencanaan strategis SI/TI Perguruan Tinggi LEPISI Tangerang. Lebih lanjut implementasi kerangka kerja perencanaan strategi SI/TI yang dimaksud dijelaskan berikut ini.

\subsection{Tahapan Kerangka Kerja Perencanaan Strategis SI/TI yang Diusulkan}

Berikut ini tahapan kerangka kerja perencanaan strategis SI/TI yang penulis usulkan adalah:

\section{Tahap-1: Mempersiapkan Perencanaan Strategi SI/TI.}

1. Tujuan perencanaan strategis SI/TI Perguruan Tinggi LEPISI Tangerang yaitu:

a. Mendapatkan keunggulan kompetitif bagi Perguruan Tinggi LEPISI dengan menggunakan dukungan sistem informasi dan teknologi informasi (SI/TI).

b. Mempertahankan keunggulan kompetitif tersebut (sustainability of competitive advantage).

2. Sasaran perencanaan strategis SI/TI Perguruan Tinggi LEPISI Tangerang yaitu:

a. Untuk menanggulangi keterbatasan sumber daya yang ada.

b. Meningkatkan sumber daya yang ada.

c. Meningkatkan penerimaan perguruan tinggi LEPISI.

d. Menjaga agar tidak kelebihan investasi dan juga kekurangan investasi.

3. Ruang lingkup perencanaan strategis SI/TI Perguruan Tinggi LEPISI dalam implementasi ini sesuai yaitu aktifitas utama adalah pendidikan dan pengajaran dan aktifitas pendukung adalah administrasi mahasiswa, administrasi keuangan, administrasi sumber daya manusia.

4. Pendekatan yang digunakan daam perencanaan strategis SI/TI Perguruan Tinggi LEPISI adalah sesuai dengan usulan kerangka kerja perencanaan strategis SI/TI yang diuraikan yaitu menggunakan konsep pemikirannya Jhon Ward dan Joe Peppard.

\section{Tahap-2: Memahami Kebutuhan Bisnis Organisasi dan Informasi.}

Untuk memahami kebutuhan bisnis perguruan tinggi LEPISI saat ini, dierlukan identifikasi informasi, analisis bisnis eksternal, analisis bisnis internal, analisis SI/TI eksternal dan analisis SI/TI internal. Berikut ini portofolio untuk aplikasi yang sedang berjalan di Perguruan Tinggi LEPISI Tangerang. 
Tabel 2. Portofolio Aplikasi Berjalan

\begin{tabular}{|c|c|}
\hline Strategic & High Potential \\
\hline **Informasi Profil Perguruan Tinggi LEPISI & $\begin{array}{l}* * \text { Layanan informasi online } \\
* * \text { SIA Terpadu berbasis Web }\end{array}$ \\
\hline $\begin{array}{l}\text { ** Aplikasi Front Office Perguruan Tinggi LEPISI } \\
\text { Tangerang: } \\
\text { - Informasi Penerimaan Mahasiswa Baru (PMB) } \\
\text { - Informasi Perkuliahan } \\
\text { - Informasi Kursus } \\
\text { - Informasi Lain-lain } \\
\text { ( ) Aplikasi Back Office Perguruan Tinggi LEPISI } \\
\text { Tangerang: } \\
\text { - Registrasi Mahasiswa } \\
\text { ** Perencanaan Kuliah }\end{array}$ & $\begin{array}{l}\text { ** Layanan perpustakaan } \\
\text { online }\end{array}$ \\
\hline Key Operational & Support \\
\hline
\end{tabular}

\section{Tahap-3: Menentukan Target bagi SI/TI}

Setelah dilakukan beberapa analisis pada tahapan sebelumnya, maka kegiatan pada tahap berikutnya adalah:

Identifikasi Masalah dan Solusi Internal

a. Pendaftaran Mahasiswa Baru

Permasalahan yang dihadapi oleh perguruan tinggi LEPISI dalam melaksanakan pendaftaran mahasiswa baru adalah:

1) Sistem aplikasi yang digunakan hanya sekedar menginput data mahasiswa baru, belum terintegrasi dengan pembayaran uang pendaftaran mahasiswa baru.

2) Sistem pendataran mahasiswa baru yang saat ini belum terintegrasi dengan program studi. Dari permasalahan di atas, SI/TI dapat digunakan sebagai solusi untuk mengatasi permasalahan yaitu dengan melakukan Sistem Pendaftaran secara On-line. Proses Bisnis Sistem Pendaftaran On-line

1) Calon mahasiswa dapat mengakses informasi syarat pendaftaran mahasiswa baru melalui website (www.lepisi.ac.id)

2) Pengisian formulir pendaftaran elektronis pada web tersebut.

3) Setelah sukses, pengisian formulir elektronis tersebut dan diberikan nomor pendaftaran ujian saringan masuk (USM) yang dapat di cetak langsung melalui web.

4) Setelah mendapatkan nomor USM, calon mahasiswa melakukan pembayaran uang pendaftaran ke bank yang sudah ditentukan oleh perguruan tinggi LEPISI dengan menuliskan nomor pendaftaran yang didapat dari web LEPISI.

b. Pelaksanaan Ujian Saringan Masuk

Permasalahannya adalah pelaksanaan ujian saringan masuk (USM) yang dilakukan terpusat yaitu di kampus LEPISI cukup merepotkan pendaftar yang berasal dari luar kota. Solusinya adalah tempat pelaksanaan ujian saringan masuk tidak hanya dilakukan secara terpusat, tetapi juga dapat dilakukan di beberapa lokasi kota sesuai dengan besarnya minat calon mahasiswanya.

c. Registrasi Mahasiswa

Registrasi mahasiswa baik yang baru maupun lama dilakukan secara manual Permasalahannya data-data yang diisi oleh mahasiswa tersebut dalam formulir belum bisa dimanfaatkan dengan baik, karena data-data tersebut masih bersifat manual. Dari permasalahan di atas, SI/TI dapat menjadi solusi untuk mengatasi permasalahan yang dihadapi pada saat proses registrasi mahasiswa, yaitu dengan menggunakan Sistem Biodata Mahasiswa On-line.

d. Perencanaan Studi Mahasiswa

Sistem perencanaan studi mahasiswa selama ini teah dilakukan dengan menggunakan sistem aplikasi melalui tahapan dan prosedur penyerahan Form Rencana Studi (FRS) dan pembagian 
Kartu Rencana Studi (KRS). Permasalahannya waktu yang diperlukan dalam proses pengisian KRS hingga penyerahan KRS membutuhkan waktu yang relatif lama dan biaya, untuk itu perlu dilakukan perubahan dalam tahapan ini. Solusi dari permasalahan persetujuan KRS dengan ketua program studi dan Puket I atau Pudir I disatukan sehingga cukup hanya Puket I atau Pudir I, sehingga form KRS harus diedit. Proses penyatuan persetujuan ini sangat efesien waktu,KRS yang dicetak cukup rangkap dua (mahasiswa dan arsip).

\subsection{Identifikasi Peluang Bisnis dari Eksternal Organisasi}

Dengan memperbaiki sistem yang ada saat ini, peluang bisnis dari eksternal organisasi dapat ditingkatkan.

a. Sistem Pendaftaran secara On-line

Sistem pendaftaran secara on-line dapat meningkatkan minat calon mahasiswa baru untuk mendaftar ke perguruan tinggi LEPISI, dimana setiap mahasiswa diberikan alternatif untuk mendaftar melalui internet dan tidak harus datang ke kampus LEPISI.

b. Pelaksanaan Ujian Saringan Masuk

Pelaksanaan ujian saringan masuk (USM) di beberapa tempat dapat meningkatkan minat mahasiswa melakukan pendaftaran ke perguruan tinggi LEPISI.

\subsection{Analisis Kesenjangan (Gap Analisis)}

Dari hasil analisis terhadap kebutuhan akan SI/TI dan SI/TI yang tersedia maka didapat point pengembangan SI/TI yang belum ada dan perbaikan terhadap SI/TI saat ini yang sudah ada tetapi belum dapat dimanfaatkan secara optimal. Selain itu perlu penambahan fiture terhadap aplikasi yang sudah ada tetapi belum dapat memenuhi kebutuhan SI yang perlu dikembangkan.

a. Sistem pendaftaran saat ini dengan sistem pendaftaran secara on-line yang akan direncanakan ke depan tentu mempunyai perbedaan dalam beberapa prosedur dalam mendapatkan kebutuhan informasinya.

b. Sistem Registrasi On-line

Sistem registrasi on-line dengan registrasi yang lama mempunyai kebutuhan data yang berbeda, di mana setiap registrasi on-line, arsipnya sudah dalam bentuk data elektronik, sedangkan yang lama masih dalam bentuk dokumen manual.

c. Sistem Perencanaan Studi Mahasiswa

Sistem perencanaan studi mahasiswa yang lama dengan yang diusulkan dalam kebutuhan datanya juga mengalami perubahan proses.

\subsection{Membuat Dasar Kebijakan SI/TI}

Berdasarkan kebijakan-kebijakan SI/TI dalam mengatasi permasalahan yang ada di atas perlu dilakukan aturan-aturan untuk mendukung kebijakan tersebut.

a. Adanya Kebutuhan Sistem Informasi yang Berbasis TI

Sistem Informasi yang berbasis teknologi informasi bagi Perguruan Tinggi LEPISI Tangerang bukan lagi suatu pilihan akan tetapi sudah merupakan suatu kebutuhan dalam proses kegiatan operasional kesehariannya.

b. Adanya Permasalahan dalam Proses Bisnis

Permasalahan-permasalahan yang ada dalam setiap proses bisnis yang ada di Perguruan Tinggi LEPISI harus dicari solusinya yaitu dengan pengembangan sistem informasi dengan memanfaatkan teknologi informasi secara optimal.

c. Peluang Pengembangan Organisasi

Sistem Informasi dengan memanfaatan teknologi secara optimal akan memberikan banyak peluang bagi pengembangan Perguruan Tinggi LEPISI Tangerang. Proses bisnis yang ditunjang oleh sistem informasi yang berbasis teknologi informasi akan lebih efisien dan efektif.

\section{Tahap-4 : Menentukan Strategi SI/TI}

Berdasarkan kebutuhan tersebut di atas diperlukan strategi SI/TI pada masa yang akan datang yang diperlukan oleh perguruan tinggi LEPISI Tangerang. 


\section{JURNAL PETIR}

Vol. 12, No. 1, Maret 2019, P-ISSN 1978-9262, E-ISSN 2655-5018

Perencanaan Strategi Bisnis SI/TI

a. Visi

Secara umum, visi bisnis SI adalah mendukung kebutuhan bisnis dan keseluruhan tujuan strategi bisnis. Dengan TI, masyarakat dan mahasiswa, dosen, administrator dan pengelola memiliki saluran informasi yang dapat diakses dengan mudah, baik untuk aktifitas transaksi atau pencarian informasi. Kebutuhan bisnis yang dimaksud adalah:

1) Berfokus pada operasional

2) Memperbaiki manajemen informasi dan pengelolaan TI

3) Meningkatkan penyebaran pengetahuan

b. Tujuan

Visi SI/TI diimplementasikan dengan strategi:

1) Perbaikan informasi sistem yang memiliki prioritas tinggi

2) Perbaikan teknologi infrastruktur untuk mendukung sistem informasi

3) Penyempurnaan Pengelolaan TI

4) Pembangunan aplikasi yang sesuai dengan kebutuhan untuk mengefesiensikan proses bisnis organisasi.

Strategi bisnis TI/SI yang perlu dijalankan oleh perguruan tinggi LEPISI pada masa yang akan datang adalah menentukan warna (keunggulan) dari masing-masing program studi sehingga calon mahasiswa lebih mengetahui program studi yang sesuai dengan minat dan bakatnya, pendaftaran mahasiswa baru dapat dilakukan melalui internet sebagai alaternatif lain bagi calon mahasiswa baru, peningkatan kualitas dosen dan staf terus dilanjutkan untuk mengikuti perkembangan SI/TI yang mutakhir.

\subsection{Perencanaan Strategis SI/TI}

Strategi SI/TI yang perlu ditingkatkan dalam mendukung strategis bisnis yang harus dijalankan oleh perguruan tinggi LEPISI pada masa yang akan datang sebagai berikut:

a. Infrastruktur Fisik

Berdasarkan analisa lingkungan bisnis berikut infrastruktur IS/IT yang telah ada serta tingkat kebutuhan pada masa mendatang maka terdapat sejumlah penambahan khususnya dari sisi arsitektur infrastruktur jaringan dalam rangka menunjang rencana strategis organisasi. Berikut ini sejumlah list detail strategi khususnya infrastruktur IT/IS yang perlu dilakukan pada masa yang akan datang:

1) Jaringan lokal (LAN) dengan tipologi bintang (star) bersifat Client-Server menggunakan kabel UTP. Untuk koneksi LAN dengan internet gunakan fasilitas speedy telkom dengan bandwidth 4 Mega Byte pada sisi backbone jaringan melalui penggunaan teknologi/protokol Ethernet melalui media fiber optic.

2) Migrasi layanan direktori dari Netware Directory Service menuju Microsoft Active Directory. Langkah ini diambil guna memastikan kesiapan Perguruan Tinggi LEPISI dalam mendukung protokol komunikasi data TCP/IP yang notabene merupakan standard de facto terhadap protokol komunikasi data untuk dunia internet

3) Melakukan implementasi database server. Solusi ini ditujukan untuk menyimpan data Perguruan Tinggi LEPISI.

4) Melakukan implementasi web server dengan menggunakan Microsoft IIS 6.0 yang berjalan pada sistem operasi Microsoft Windows 2003 Web Edition.

5) Membuat hotspot Wifi untuk kemudahan bagi mahasiswa dan dosen untuk mengakses informasi di lingkungan perguruan tinggi LEPISI.

\section{Portofolio Aplikasi SI Mendatang}

a. Portofolio Aplikasi

Berikut ini merupakan bentuk dari matriks portofolio aplikasi yang penulis usulkan: 
Tabel 3. Portofolio Aplikasi Berjalan dan Usulan

\begin{tabular}{|c|c|c|c|}
\hline Keterangan & Aplikasi Berjalan & Aplikasi Usulan & Gap Analisis \\
\hline Strategic & $\begin{array}{l}\text { **Informasi Profil } \\
\text { Perguruan Tinggi } \\
\text { LEPISI }\end{array}$ & $\begin{array}{l}\text { *** Informasi Profile } \\
\text { Perguruan Tinggi LEPISI } \\
\text { online }\end{array}$ & $\begin{array}{l}\text { Perlu dibuat web } \\
\text { Perguruan Tinggi } \\
\text { LEPISI }\end{array}$ \\
\hline $\begin{array}{l}\text { Key } \\
\text { Operational }\end{array}$ & $\begin{array}{l}\text { ** Aplikasi Front } \\
\text { Office Perguruan } \\
\text { Tinggi LEPISI } \\
\text { Tangerang: } \\
\text { - Informasi } \\
\text { Penerimaan } \\
\text { Mahasiswa Baru } \\
\text { (PMB) } \\
\text { - Informasi } \\
\text { Perkuliahan } \\
\text { - Informasi Kursus } \\
\text { - Informasi Lain-lain } \\
\text { ( ) Aplikasi Back Office } \\
\text { Perguruan Tinggi } \\
\text { LEPISI Tangerang: } \\
\text { - Registrasi } \\
\text { Mahasiswa } \\
\text { ** Perencanaan } \\
\text { Kuliah }\end{array}$ & $\begin{array}{l}\text { **Aplikasi Front Office } \\
\text { Perguruan Tinggi LEPISI } \\
\text { Tangerang: } \\
\text { - Informasi Penerimaan } \\
\text { Mahasiswa Baru (PMB) } \\
\text { - Informasi Kursus } \\
\text { - Informasi Perkuliahan } \\
\text { - Informasi Lain-lain } \\
\text { **Aplikasi Back Office } \\
\text { Perguruan Tinggi LEPISI } \\
\text { - } \text { Modine: } \\
\text { - Madul Registrasi } \\
\text { - Modul Administrasi } \\
\text { keuangan } \\
\text { - Modul Internal Akademik } \\
\text { - Modul Kepegawaian } \\
\text { - Modul Penerimaan } \\
\text { Mahasiswa Baru }\end{array}$ & $\begin{array}{l}\text { Modul aplikasi } \\
\text { berjalan hanya bisa } \\
\text { digunakan untuk } \\
\text { penanganan registrasi } \\
\text { mahasiswa dan belum } \\
\text { terintegrasi dengan } \\
\text { bagian lain yang } \\
\text { terkait. } \\
\text { Perlu pengembangan } \\
\text { fitur aplikasi untuk } \\
\text { front office maupun } \\
\text { back office dengan } \\
\text { menambah beberapa } \\
\text { modul yang } \\
\text { dibutuhkan dan } \\
\text { terintegrasi dengan } \\
\text { bagian lain yang } \\
\text { terkait. }\end{array}$ \\
\hline $\begin{array}{l}\text { High } \\
\text { Potential }\end{array}$ & $\begin{array}{l}\text { ** Layanan informasi } \\
\text { online } \\
\text { ** SIA Terpadu } \\
\text { berbasis Web }\end{array}$ & $\begin{array}{l}\text { *** ayanan Pendaftaran } \\
\text { Online } \\
\text { ** Sistem Informasi } \\
\text { Akademik Berbasis } \\
\text { Web }\end{array}$ & $\begin{array}{l}\text { Fitur Layanan } \\
\text { pendaftaran online } \\
\text { akan memberikan } \\
\text { kemudahan kepada } \\
\text { calon mahasiswa }\end{array}$ \\
\hline Support & $\begin{array}{l}\text { ** Layanan } \\
\text { perpustakaan online }\end{array}$ & ** Perpustakaan Online & $\begin{array}{l}\text { Sebagai pendukung } \\
\text { referensi akademik }\end{array}$ \\
\hline
\end{tabular}

Ket Sistem sudah tersedia dan cukup memuaskan

( ) Sistem sudah tersedia tetapi perlu improvement

** Sistem yang akan direncanakan

** Belum tersedia dan harus dikembangkan

\subsection{Perencanaan Strategi Manajemen SI/TI}

Manajemen SI/TI pada masa yang akan datang sebaiknya dipegang oleh satu bagian khusus untuk SI/TI yang dipimpin oleh seorang kepala bagian atau kepala Divisi TI yang bekerja sama dengan program studi dan pimpinan perguruan tinggi LEPISI agar dapat menselaraskan strategis SI/TI dengan strategi bisnis yang ingin diterapkan pada masa yang akan datang sehingga investasi di bidang SI/TI tidak hanya menjadi cost center saja.

\section{Tahap-5 : Rencana Implementasi}

Tahap ini bertujuan untuk membuat rencana dan jadwal kerja guna mengimplementasikan solusi SI/TI. Dari portofolio aplikasi masa yang akan datang tersebut dibuatlah sebuah rencana kegiatan sebagai pedoman yang dapat dilihat pada tabel 4 berikut: 
Tabel 4. Rencana Implementasi

\begin{tabular}{|c|c|c|c|c|}
\hline Pekerjaan & Nhilestanes & Waktu & Tantangan & Solugi \\
\hline Perbaikan infrastruktur & $\begin{array}{ll}\text { 1. } & \text { Upgrade bandwidth } \\
\text { 2. } & \text { Penyediaan Server } \\
\text { 3. } & \text { Migrasi database server } \\
\text { 4. } & \text { Implementasi web server }\end{array}$ & 6 Bulan & - Investasi Tinggi & - Dilakukan sec ara bertahap \\
\hline Perbaikan aplikasi bejalan & $\begin{array}{l}\text { 1. Evaluasi perubahan platform } \\
\text { 2. Re-Development } \\
\text { 3. Migrasi aplikasi } \\
\text { 4. Sosialisasi Pengguna }\end{array}$ & $\begin{array}{l}\text { 1. } 6 \text { Bulan } \\
\text { 2. } 12 \text { Bulan } \\
\text { 3. } 6 \text { Bulan } \\
\text { 4. } 6 \text { Bulan }\end{array}$ & $\begin{array}{l}\text { Operasional yang akan terganggu } \\
\text { - } \\
\text { Keengganan pengguna terhadap teknologi } \\
\text { baru } \\
\text { - Biaya pengembangan yang tidak murah }\end{array}$ & $\begin{array}{l}\text { Adanya fase-fase implementasi } \\
\text { yang bertahap } \\
\text { - Adanya dukungan manajemen } \\
\text { bagi penggunaan aplikasi dengan } \\
\text { platform baru } \\
\text { - Adanya alokasi dana yang cukup }\end{array}$ \\
\hline $\begin{array}{l}\text { Pembangunan aplikasi yang } \\
\text { direncanakan }\end{array}$ & $\begin{array}{ll}\text { 1. } & \text { Evaluasi prioritas } \\
\text { 2. } & \text { Pembangunan aplikasi } \\
\text { 3. } & \text { Implementasi } \\
\text { 4. } & \text { Maintenance }\end{array}$ & 6 Bulan & $\begin{array}{l}\text { - Jumlah staff yang terbatas dan keahlian yang } \\
\text { kurang } \\
\text { - Kemampuan keuangan yang terbatas } \\
\text { - Pengetahuan pengguna yang masih kurang }\end{array}$ & $\begin{array}{l}\text { - } \\
\text { - Rraining staff tentang aplikasi } \\
\text { Reknumen staff yang } \\
\text { berpengalaman } \\
\text { - Alokasi budget } \\
\text { Training pengguna }\end{array}$ \\
\hline Prosedur Operasi Standar & $\begin{array}{ll}1 . & \text { Pembuatan } \mathrm{SOP} \\
\text { 2. } & \text { Sosialisasi SOP } \\
\text { 3. } & \text { Standarisasi Aset }\end{array}$ & 12 Bulan & $\begin{array}{l}\text { - Pembuatan SOP yang sesuai dengan standar } \\
\text { dunia TI dan sesuai kebutuhan organisasi } \\
\text { Ketdaknyamanan pengguna dengan adanya } \\
\text { SOP }\end{array}$ & $\begin{array}{l}\text { - Pembuatan SOP secara bertahap } \\
\text { - Meminta dukungan manajemen } \\
\text { urtuk implementasi prosedur } \\
\text { Sosialisasi kepada selunuh } \\
\text { karyaman }\end{array}$ \\
\hline Pengembangan Staff & $\begin{array}{ll}\text { 1. } & \text { Training Staff } \\
2 . & \text { Reknutmen Staff baru }\end{array}$ & $\begin{array}{l}\text { Program berkesinambungan } \\
\text { selama } 5 \text { Tahun }\end{array}$ & $\begin{array}{l}\text { Keterbatasan dana training } \\
\text { - }\end{array}$ & $\begin{array}{l}\text { Training steff secara bergilir } \\
\text { sesuai dengan keahlian yang } \\
\text { diharapkan bagi staff } \\
\text { Adanya sesi sharing knowledge } \\
\text { antar staff } \\
\text { Adanya knowledge database } \\
\text { sistem sehingga tidak ada } \\
\text { keteryantungan temadap individu } \\
\text { Adanya pengenalan sistem kagi } \\
\text { karyauran baru }\end{array}$ \\
\hline Standarisasi Asset & Penggantian asset lama & 18 Bulan & $\begin{array}{l}\text { - Perusahaan tidak ingin membuang aset lama } \\
\text { - Pembelian aset baru yang dianggap mahal }\end{array}$ & $\begin{array}{l}\text { - Pergantian aset sec ara bertahap } \\
\text { - Pembelian aset baru sesuai } \\
\text { dengan standar yang telah } \\
\text { ditetapkan }\end{array}$ \\
\hline
\end{tabular}

\section{KESIMPULAN DAN SARAN}

Berdasarkan hasil analisis yang telah dilakukan pada bab sebelumnya, penulis mengambil beberapa simpulan, pertama hasil penelitian yang dilakukan adalah sebuah kerangka kerja rencana strategis SI/TI yang dapat digunakan pada perguruan tinggi LEPISI. Kedua usulan kerangka kerja perencanaan strategis SI/TI, pihak perguruan tinggi LEPISI dapat mengetahui faktor-faktor penting yang diperlukan dalam mengembangkan suatu sistem informasi yang selaras dengan rencana strategis perguruan tinggi LEPISI. Ketiga strategi manajemen SI/TI pada Perguruan Tinggi LEPISI Tangerang yang diturunkan dari hasil penerapan perencanaan strategis sistem informasi berupa kebijakan organisasi dalam menerapkan strategi SI/TI sesuai kondisi manajemen. Strategi manajemen diantaranya melakukan pengembangan sistem informasi pada beberapa bidang, yaitu sistem aplikasi, perangkat keras, infrastruktur TI, staf/struktur organisasi, dan layanan SI/TI. Sedangkan saran yang penulis berikan adalah perlu penambahan divisi atau departemen SI/TI pada struktur organisasi perguruan tinggi LEPISI akan mampu mengatasi kebutuhan akan pengembangan maupun perawatan hardware dan software.

\section{DAFTAR PUSTAKA}

[1] Jogiyanto.(2005). Sistem Informasi Strategik Untuk Keunggulan Kompetitif, $1^{\text {st }}$ Ed.Yogyakarta: ANDI.

[2] Indrajit, RE.(2000).Manajemen Sistem Informasi \& Teknologi Informasi. Jakarta:Elek Media Komputindo.

[3] Jogiyanto.(2005). Sistem Informasi Strategik Untuk Keunggulan Kompetitif, ${ }^{\text {st }}$ Ed.Yogyakarta: ANDI.

[4] Sugesti N,Nuranisak., \& Ali, Achmad Cholil Noor.(2009).Perencanaan Portofolio Mendatang Berdasarkan Strategis Bisnis Program Studi Sistem Informasi ITS. Jurnal Sistem Informasi ITS, 1-6.

[5] Tim Penelitian \& Pengembangan Wahana.(2003).Pembuatan Program SIA Berbasis ASP. Jakarta:Salemba. 
[6] Turban, Efrain, McFarlan E, \& Watherbe, J. ..(2003)., Information Technology for Management : Marketing Connection for Stretegic Advantage, second Edition, New York :John Wiley \& Son Inc

[7] Purwanto, Iwan. (2008).Perencanaan Strategis Sistem Informasi Studi Kasus Pada Rumah Sakit Advent Bandar Lampung.. Jakarta: Fakultas Tesis Ilmu Komputer Universitas Indonesia,

[9] Ward, John and Joe Peppard.(2002). Stretegic Planning for Information Systems, Third Edition. John Willey \& Sons.

[11] Wardani, Susy Kusuma. 2013. Sistem Informasi Pengelolaan Data Nilai Siswa Berbasis Web Pada Sekolah Menengah Pertama (SMA) Muhammdiyah Pacitan. ISSN:2302-5700. Pacitan: IJSN Volume 2 No.2 April 2013. Diambil dari http://www.ijns.org/journal/index.php/ijns/article/viewFile/188/183. (28 September 2013 )

[12] Kurnia, Tedi, Dini Destiani dan Asep Deddy Suprianti. 2012. Perancangan Sistem Informasi Akademik Nilai Siswa Berbasis Web (Studi kasus: SMK Ciledug Al-Musaddiyah Garut). ISSN:2302-7339. Garut: Jurnal Algoritma Vol.09, No17 2012. Diambil dari: http://jurnal.sttgarut.ac.id/index.php/algoritma/article/view/18/19. (September 2013) 